\title{
PERAN PENYULUH PERTANIAN DALAM PENINGKATAN TEKNOLOGI BUDIDAYA USAHATANI CABAI RAWIT (Capsicum frutescens L.)
}

\author{
Ir. Ni Nengah Yastini, M.P \\ Program Studi Agribisnis, Fakultas Pertanian Universitas Dwijendra Denpasar \\ Email: yastini008@gmail.com \\ Getrudis Nanap S.P \\ Program Studi Agribisnis, Fakultas Pertanian Universitas DwijendraDenpasar \\ Email : ghetryiz96@gmail.com
}

\begin{abstract}
Abstrak
Penyuluh adalah orang yang memiliki peran,tugas atau profesi yang memberikan pendidikan, penerangan kepada masyarakat untuk mengatasi berbagai masalah,seperti pertanian sehingga dapat mencapai sasaran yang telah ditetapkan. Adapun tujuan penelitian ini adalah untuk menjelaskan peran penyuluh pertanian dalam peningkatan teknologi budidaya usahatani cabai rawit. Penentuan lokasi ini dilakukan dengan cara purposive (secara sengaja) dengan alasan di Subak Cau Beten, Desa Sukawati, Kecamatan Sukawati, Kabupaten Gianyar merupakan salah satu daerah yang potensial untuk kegiatan produksi pertanian yaitu dengan usahatani cabai rawitnya.

Populasi penelitian ini adalah seluruh anggota petani cabai rawit yang ada di Subak Cau Beten dengan jumlah 110 orang. Jumlah sampel pada penelitian ini sebanyak 50 orang dengan menggunakan simple random sampling atau acak sederhana. Berdasarkan hasil analisis yang telah dilakukan terhadap peran penyuluh pertanian dalam peningkatan teknologi budidaya usahatani cabai rawit di Subak Cau Beten, Desa Sukawati, Kecamatan Sukawati, Kabupaten Gianyar sudah berperan dalam menjalankan tugasnya sebagai edukator dengan rata-rata pencapain skor 78,00\% dengan kisaran 68,00\% sampai dengan $88,00 \%$ dan motivator dengan rata-rata pencapaian skor adalah 77,60\% dari skor tertinggi dengan kisaran $69,00 \%$ sampai dengan $82,00 \%$. Sedangkan penyuluh belum menjalankan tugasnya sebagai komunikator dengan pencapaian skor rata-rata adalah $66,40 \%$ dari skor terendah dengan kisaran $64,00 \%$ sampai dengan $68,00 \%$ dan evaluator rata-rata pencapaian sebesar $67,20 \%$ dari skor terendah dengan kisaran $60,00 \%$ sampai dengan 68,00\%.
\end{abstract}

Kata Kunci: Peran,Penyuluh,Usahatani,Cabai Rawit

\begin{abstract}
Extension agents are people who wave roles, task or professions that provide education, information to the community to overcome various problems, such as agriculture so that they can achieve the targets set. The purpose of this study is to explain the role of agricultural extension workers in improving the technology of cayenne pepper cultivation. Determination of this location is done by purposive (deliberate) on the grounds in Subak Cau Beten, Sukawati Village, Sukawati District, Gianyar Regency is one of the potential areas for agricultural production activities, namely the farming of cayenne pepper.

The population of this study was all 110 members of cayenne pepper farmers in Subak Cau Beten. The number of samples in this study were 50 people using simple random sampling. Based on the results of an analysis conducted on the role of agricultural instructors in improving the cultivation technology of cayenne pepper farming in Subak Cau Beten, Sukawati Village, Sukawati District, Gianyar Regency has played a role in carrying out their duties as an educator with an average score of $78.00 \%$ with a range of $68.00 \%$ up to $88.00 \%$ and and motivators with an average achievement score is $77.60 \%$ of the highest score in the range of $69.00 \%$ to $82.00 \%$. While extension agents have not carried out their duties as communicators with an average score achievement of $66.40 \%$ of the lowest score in the range of $64.00 \%$ to $68.00 \%$ and an average evaluator of achievement of $67.20 \%$ of the lowest score with a range of $60.00 \%$ up to $68.00 \%$

Keywords: Role, Extension, Farming, Chili Rawit
\end{abstract}

\section{PENDAHULUAN}

Pembangunan pertanian di indonesia telah dilaksanakan secara bertahap dan berkelanjutan dengan harapan dapat meningkatkan produksi pertanian semaksimal mungkin sehingga dapat meningkatkan pendapatan petani dalam mencapai kesejahteraan. Namun taraf hidup sebagian petani di indonesia belum 
maksimal. Oleh karena itu, dibutuhkannya kegiatan penyuluhan pertanian yang mampu mencukupi kebutuhan petani dalam hal kegiatan pertanian.penyuluhan pertanian telah memainkan peranan penting dalam peningkatan produksi pertanian di Indonesia (Sedana and Rahmat, 2020). Pembangunan nasional merupakan proses transformasi dari pertanian tradisional menjadi pertanian tangguh yang mampu memanfaatkan sumber daya secara optimal, mampu melakukan penyesuaian diri dalam pola dan struktur produksinya terhadap perubahan sikap, perilaku, pengetahuan dan keterampilan petani dan keluarganya sebagai hasil dari proses belajar mengajar. Penyuluhan pertanian merupakan pendidikan non formal bagi petani yang meliputi kegiatan dalam ahli pengetahuan dan keterampilan dari penyuluh kepada petani dan keluarganya yang berlangsung melalui proses belajar mengajar (Mardikanto, 2009).

Penyuluhan pertanian adalah suatu usaha atau upaya untuk mengubah perilaku petani dan keluarganya,agar mereka mengetahui dan mempunyai kemauan serta mampu memecahkan masalah sendiri dalam usaha atau kegiatan-kegiatan meningkatkan hasil usahanya dan tingkat kehidupannya. Menurut Samsudin (1994) penyuluhan pertanian adalah suatu cara atau usaha pendidikan yang bersifat di luar bangku sekolah (non-formal) untuk para petani dan keluarganya di pedesaan.

Peran agen penyuluh pertanian adalah membantu petani membentuk pendapatan yang sehat dan membuat keputusan yang baik dengan cara berkomunikasi dan memberikan informasi yang mereka perlukan. Peran agen penyuluh pertanian adalah mempromosikan dan melengkapi proses belajar mereka.Dalam melakukannya,agen penyuluhan akan memperbaiki citranya sendiri mengenai kenyataan dengan belajar dari petani ( Van Den Ban dan Hawkins,1999).

Penyuluh pertanian harus ahli pertanian yang berkompeten, disamping bisa membimbing para petani, penyuluh juga memberikan motivasi, memberikan informasi dan meningkatkan kesadaran petani sehingga dapat mendorong minat belajar mereka dalam menghadapi permasalahan di lapanagan.dengan adanya penyuluh diharapkan semua informasi pertanian yang berkembang dapat diserap dan di terima oleh petani, semakin banyak informasi yang dimanfaatkan oleh petani maka semakin efektif penyuluhan tersebut.salah satu komponen dalam sistem agribisnis, maka peran kelompok tani sangat menentukan keberhasilan penyuluhan (Ban,1999).

Penyuluhan dapat mempengaruhi sasaran melalui perannya sebagai edukator, motivator, komunikator dan evaluator (Mardikanto, 2009) yang sesuai dengan karakteristik/ciri petani termasuk potensi wilayah. Untuk meningkatkan efektivitas dari kegiatan penyuluhan guna menumbuh dan mengembangkan peran serta petani dalam pembangunan pertanian, maka perlu dilakukan pembinaan terhadap kelompok tani yang terbentuk sehingga nantinya kelompok tani tersebut akan mampu untuk tumbuh dan berkembang menjadi kekuatan ekonomi yang memadai dan selanjutnya akan mampu menopang kesejahteraananggotannya.

Menurut Kartasapoetra (1994), dalam perencanaan dan pelaksanaan penyuluhan pertanian harus mencakup tujuan jangka pendek dan jangka panjang. Tujuan penyuluhan jangka pendek yaitu untuk menumbuhkan perubahan-perubahan yang lebih terarah dalam aktivitas usahatani pedesaan antara lain, tingkat pengetahuan, kecakapan atau kemampuan sikap dan tindakan petani. Adapun tujuan penyuluhan pertanian jangka panjang yaitu agar tercapai peningkatan taraf hidup masyarakat petani, kesejahteraan 
hidup yang lebih terjamin. Tujuan ini hanya dapat tercapai apabila petani dalam masyarakat itu, pada umumnya telah melakukan "better farming, better business, dan better living”. Keberadaan lembaga keuangan di desa, seperti Lembaga Perkreditan Desa juga memberikan dukungan di dalam penyediaan tambahan modal usahantani (Sedana, 2018).

Peran penyuluh dalam kelompok tani perlu dilaksanakan dengan nuansa partisipatif sehingga prinsip kesetaraan, transparansi, tanggung jawab serta kerjasama menjadi muatan-muatan baru dalam pemberdayaan petani. Suatu kelompok tani yang terbentuk atas dasar adanya kesamaan kepentingan diantara petani menjadikan kelompok tani tersebut dapat eksis dan memiliki kemampuan untuk melakukan akses kepada seluruh sumber daya seperti sumber daya alam, manusia, modal, informasi, serta sarana dan prasarana dalam pengembangan usahatani yang dilakukannya (Jasmal,2007; Sedana and Astawa, 2019).

Pentingnya peran penyuluh sangat dirasakan manfaatnya di subak cau, desa sukawati, kecamatan sukawati kabupaten gianyar. Subak cau beten adalah salah satu daerah yang potensial untuk pengembangan tanaman cabai rawit di mana produksi cabai rawit mempunyai peluang yang cukup besar di pasar seperti halnya sayuran dan buah-buahan.subak cau beten merupakan salah satu daerah yang masih memandang perluhnya penyuluhan dalam peningkatan teknologi budidaya usahatani cabai rawit. Hal ini disebabkan karena kondisi lahan yang cukup dan mendukung kelompok tani dalam meningkatkan usahatani cabai rawit dan hasilproduksinya.

Untuk melihat seberapa besar peran penyuluh terhadap perkembangan budidaya usahatani cabai rawit di subak cau beten, peneliti kemudian merasa tertarik untuk membahas lebih lanjut dengan menuangkanya dalam bentuk usulan penelitian yang berjudul "peran penyuluh pertanian dalam peningkatkan teknologi budidaya usahatani cabai rawit (capsicum frutescensl.) Kasus di Subak Cau Beten, Desa Sukawati, Kecamatan Sukawati, Kabupaten Gianyar”

\section{METODE}

Penelitian ini dilakukan di Subak Cau Beten, Desa Sukawati, Kecamatan Sukawati, Kabupaten Gianyar. Penentuan lokasi ini dilakukan secara sengaja (purposive) dengan dasar pertimbangan yaitu di Subak Cau, Desa Sukawati, Kecamatan Sukawati, Kabupaten Gianyar. Populasi dalam penelitian ini adalah para anggota petani yang mengusahakan budidaya tanaman cabai rawit sebanyak 110 orang petani.Adapun sampel dari penelitian ini yaitu sebanyak 50 petani yang dipilih secara simple random sampling.

Jenis data yang digunakan dalam penelitian ini adalah data kualitatif dan data kuantitatif dengan sumber data primer dan data sekunder. Teknik pengumulan data dalam penelitian ini menggunakan metode Metode Kuisioner, Wawancara, Observasi dan Dokumentsi. Metode analisis yang digunakan dalam penelitian ini adalah analisis data kualitatif, dari jawaban responden pada kuisioner diperoleh data yang kemudian dianalisis dengan menggunakan metode skor.Semua kriteria penilaian peran penyuluh pertanian diberi skor yang telah ditentukan. Cara yang digunakan dalam penyusunan data tersebut adalah menggunakan skala likert,dimana skor responden dijumlahkan,ini merupakan total skor kemudian di hitung rata-ratanya,dan rata-rata inilah yang ditafsirkan sebagai posisi penilaian responden pada skala likert sehingga mempermudah dalam mengelompokan dan mempersentasekan data. 


\section{HASIL DAN PEMBAHASAN}

\section{Peran Penyuluh SebagaiEdukator}

Hasil penelitian yang dilakukan terhadap 50 petani sampel diperoleh informasi bahwa rataratapencapaian skor peran penyuluh sebagai edukator adalah 78,00\% dari skor tertinggi dengan kisaran $66,00 \%$ sampai dengan $88,00 \%$.Secara lebih rinci,distribusi frekuensi petani sampel berdasarkan peran penyuluh sebagai edukator 1 .

Tabel 1. Distribusi Frekuensi Petani Sampel Berdasarkan Peran Penyuluh Sebagai Edukator

\begin{tabular}{|ll|c|c|}
\hline \multicolumn{1}{|c|}{ Kategori } & Frekuensi (orang) & Prosentase (\%) \\
\hline 1. & Sangattinggi & 3 & 6,00 \\
2. & Tinggi & 39 & 78,00 \\
3. & Sedang & 8 & 16,00 \\
4. & Rendah & 0 & 0,00 \\
5. & Sangatrendah & 0 & 0,00 \\
\hline & Jumlah & 50 & 100 \\
\hline
\end{tabular}

Sumber :Data Primer 2019

Berdasarkan pada Tabel 1 terlihat bahwa tidak ada petani yang menyatakan peran penyuluh sebagai edukator sangat rendah.Sebagian besar petani sampel 78,00\% menyatakan penyuluh telah berperan dalam menjalankan tugasnya sebagai edukator dan 16,00\% petani sampel mengatakan penyuluh belum sepenuhnya berperan dalam menjalankan tugasnya sebagai edukator.Seperti halnya pada variabel peran penyuluh sebagai edukator ini di ukur beberapa indikator yaitu (i) penyuluh meningkatkan pengetahuan petani terhadap ide baru untuk peningkatan usaha kelompok tani cabai rawit,(ii) penyuluh melatih keterampilan petani cabai rawit terhadap ide baru.(iii) penyuluh memiliki kemampuan dalam melatih petani dalam peningkatan usaha kelompok tani cabai rawit.Secara lebih rinci,distribusi frekuensi petani berdasarkan pada indikator-indikator tersebut disajikan pada Tabel 2.

Tabel 2. Distribusi Frekuensi Petani Berdasarkan pada Indikator-indikator yang Diukur

\begin{tabular}{|l|c|c|}
\hline \multicolumn{1}{|c|}{ Kategori } & Frekuensi (orang) & Prosentase (\%) \\
\hline A. Pengetahuan petani & 3 & 6,00 \\
1. Sangattinggi & 40 & 80,00 \\
2. Tinggi & 7 & 14,00 \\
3. Sedang & 0 & 0,00 \\
4. Rendah & 0 & 0,00 \\
5. Sangatrendah & 50 & 100 \\
\hline$\quad$ Jumlah & 2 & \\
\hline B. Melatihpetani & 39 & 4,00 \\
1. Sangattinggi & 9 & 78,00 \\
2. Tinggi & 0 & 18,00 \\
3. Sedang & 0 & 0,00 \\
4. Rendah & & 0,00 \\
5. Sangatrendah & 50 & 100 \\
\hline Jumlah & & \\
\hline C. Kemampuan melatihpetani & 0 & 0,00 \\
1. Sangattinggi & 39 & 78,00 \\
2. Tinggi & 11 & 22,00 \\
3. Sedang & 0 & 0,00 \\
4. Rendah & 0 & 0,00 \\
5. Sangatrendah & & \\
6. & 50 & 100 \\
\hline \multicolumn{1}{l}{ Jumlah } & & \\
\hline Sumber : Data Prime & \\
\hline
\end{tabular}

Sumber : Data Primer 2019 
Dari Tabel 2 di atas dapat dilihat bahwa petani sampel yang menyatakan penyuluh berperan dalam meningkatkan pengetahuan petani terhadap ide baru dalam peningkatan usaha kelompok tanisangat tinggi yaitu sebesar $6,00 \%$.Alasan petani menyatakan penyuluh berperan adanya pelatihan dalam melaksanakan pembuatan pupuk kompos secara organik yang belum pernah dilakukan oleh kelompok tani,adanya budidaya tanaman cabai sehat yang diberikan oleh penyuluh yang meningkatkan produksi petani.Sedangkan $22,00 \%$ petani sampel yang menyatakan penyuluh memiliki kemampuan dalam melatih petani dalam peningkatan usaha kelompok tani cabai rawit.Alasan petani menyatakan penyuluh berperan karena penyuluh memberikan pelatihan tentang pengendalian hama penyakit,penyuluh juga memberikan materi sesuai yang dibutuhkan kelompok tani cabairawit.

\section{Peran Penyuluh Sebagai Motivator}

Hasil penelitian yang dilakukan terhadap 50 petani sampel diperoleh informasi bahwa rata-rata pencapaian skor peran penyuluh sebagai motivator adalah $77,60 \%$ dari skor tertinggi dengan kisaran $69,00 \%$ sampai dengan $82,00 \%$.Secara lebih rinci,distribusi frekuensi petani berdasarkan peran penyuluh sebagai motivator dapat dilihat pada tabel 3 .

Tabel 3. Distribusi Frekuensi Petani sampel berdasarkan peran penyuluh sebagai motivator

\begin{tabular}{|l|c|c|}
\hline \multicolumn{1}{|c|}{ Kategori } & Frekuensi (orang) & Porsentase(\%) \\
\hline 1. Sangattinggi & 2 & 4,00 \\
2. Tinggi & 40 & 80,00 \\
3. Sedang & 8 & 16,00 \\
4. Rendah & 0 & 0 \\
5. Sangatrendah & 0 & 0 \\
\hline Jumlah & 50 & 100 \\
\hline
\end{tabular}

Sumber: Data Primer 2019

Berdasarkan pada tabel 3 terlihat bahwa tidak ada petani yang menyatakan peran penyuluh sebagai motivator sangat rendah. Sebagian besar petani sampel 80,00\% menyatakan penyuluh telah berperan dalam menjalankan tugasnya sebagai motivator dan $4,00 \%$ petani sampel menyatakan penyuluh belum sepenuhnya menjalankan tugasnya sebagai motivaror. Dalam penelitian ini diukur beberapa indikator di dalam penyuluh sebagai motivator yaitu (i) penyuluh mendorong petani untuk mengembangkan usaha cabai rawit,(ii) penyuluh mendorong petani menggunakan kemudahan teknologi dalam berusahatani cabai rawit,dan (iii) penyuluh membantu petani dalam mengarahkan usahatani cabai rawit.Secara lebih rinci ,distribusi frekuensi petani berdasarkan pada indikator-indikator tersebut disajikan pada tabel 4.

Tabel 4. Distribusi Frekuensi Petani Berdasarkan pada Indikator-indikator yang Diukur

\begin{tabular}{|l|c|c|}
\hline \multicolumn{1}{|c|}{ Kategori } & Frekuensi (orang) & $\begin{array}{c}\text { Prosentase } \\
(\%)\end{array}$ \\
\hline A. Mengembangkan usahatani & 16,00 \\
1. Sangattinggi & 8 & 80,00 \\
2. Tinggi & 40 & 4,00 \\
3. Sedang & 2 & 0,00 \\
4. Rendah & 0 & 0,00 \\
5. Sangatrendah & 0 & 100 \\
\hline Jumlah & 50 & \\
\hline
\end{tabular}




\begin{tabular}{|c|c|c|}
\hline $\begin{array}{l}\text { B. Kemudahan teknologi } \\
\text { 1. Sangattinggi } \\
\text { 2. Tinggi } \\
\text { 3. Sedang } \\
\text { 4. Rendah } \\
\text { 5. Sangatrendah }\end{array}$ & $\begin{array}{c}2 \\
40 \\
8 \\
0 \\
0\end{array}$ & $\begin{array}{c}4,00 \\
80,00 \\
16,00 \\
0,00 \\
0,00\end{array}$ \\
\hline Jumlah & 50 & 100 \\
\hline 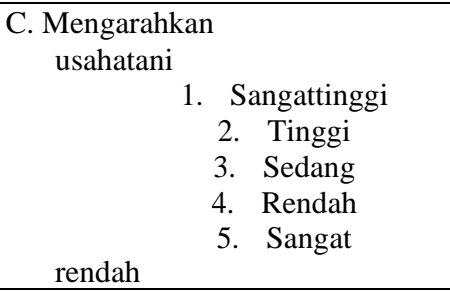 & $\begin{array}{c}6 \\
42 \\
2 \\
0 \\
0\end{array}$ & $\begin{array}{r}12,00 \\
84,00 \\
4,00 \\
0,00 \\
0,00\end{array}$ \\
\hline Jumlah & 50 & 100 \\
\hline
\end{tabular}

Sumber : Data Primer 2019

Dari Tabel 4 diatas bahwa petani sampel yang meyatakan penyuluh mendorong petani menggunakan kemudahan teknologi dalam berusahatani cabai rawit adalah sangat tinggi yaitu 16,00\%.Alasan petani menyatakan penyuluh berperan karena penyuluh menyampaikan teknologi yang tepat guna meningkatkankan hasil produksi cabai rawit dengan menggunakan pupuk kompos dengan cara mempraktekan langsung.Sedangkan 4,00\% petani sampel menyatakan penyuluh belum sepenuhnya berperan membantu petani dalam meningkatkan hasil produksi cabai rawit.

\section{Peran Penyuluh Sebagai Komunikator}

Hasil penelitian yang dilakukan terhadap 50 petani sampel diperoleh informasi bahwa rata-rata pencapaian skor peran penyuluh sebagai komunikator adalah $66,40 \%$ dari skor terendah dengan kisaran $64,00 \%$ sampai dengan 68,00\%.Secara lebih rinci,distribusi frekuensi petani berdasarkan peran penyuluh sebagai komunikator dapat dilihat pada tabel 5.

Tabel 5. Distribusi Frekuensi Petani Sampel Berdasarkan Peran Penyuluh sebagai Komunikator

\begin{tabular}{|l|c|c|}
\hline \multicolumn{1}{|c|}{ Kategori } & Frekuensi (orang) & Porsentase (\%) \\
\hline 1. Sangattinggi & 2 & 4,00 \\
2. Tinggi & 18 & 36,00 \\
3. Sedang & 22 & 44,00 \\
4. Rendah & 8 & 16,00 \\
5. Sangatrendah & 0 & 0,00 \\
\hline \multicolumn{1}{|c|}{ Jumlah } & 50 & 100 \\
\hline
\end{tabular}

Sumber :Data Primer 2019

Dari tabel 5 di atas dapat dilihat bahwa petani sampel yang menyatakan penyuluh telah berperan menjalankan tugasnya sebagai komunikator yaitu sebesar 4,00\% sedangkan 44,00\% petani sampel menyatakan penyuluh belum sepenuhnya berperan dalam menjalankan tugasnya sebagai komunikator.Dalam penelitian ini diukur beberapa indikator-indikator yaitu : (i) penyuluh membantu percepat arus informasi petani cabai rawit,(ii) penyuluh membantu petani dalam proses pengambilan keputusan terhadap petani cabai rawit,dan (iii) penyuluh memiliki kemampuan komunikasi yang baik dengan petani cabai rawit. Secara lebih rinci,distribusi frekuensi petani sampel berdasarkan pada indikator-indikator tersebut disajikan pada Tabel 6. 
Tabel 6. Distribusi Frekuensi Petani Sampel Berdasarkan Indikator-indikator yang Diukur

\begin{tabular}{|c|c|c|}
\hline Kategori & Frekuensi (orang) & Porsentase (\%) \\
\hline $\begin{array}{l}\text { A.Percepat arusinformasi } \\
\text { 1. Sangattinggi } \\
\text { 2. Tinggi } \\
\text { 3. Sedang } \\
\text { 4. Rendah } \\
\text { 5. Sangatrendah }\end{array}$ & $\begin{array}{c}8 \\
40 \\
2 \\
0 \\
0\end{array}$ & $\begin{array}{r}16,00 \\
80,00 \\
4,00 \\
0,00 \\
0,00\end{array}$ \\
\hline Jumlah & 50 & 100 \\
\hline $\begin{array}{l}\text { B.Pengambilan keputusan } \\
\text { 1.Sangattinggi } \\
\text { 2.Tinggi } \\
\text { 3.Sedang } \\
\text { 4.Rendah } \\
\text { 5.Sangatrendah }\end{array}$ & $\begin{array}{c}6 \\
40 \\
4 \\
0 \\
0\end{array}$ & $\begin{array}{c}12,00 \\
80,00 \\
8,00 \\
0,00 \\
0,00\end{array}$ \\
\hline Jumlah & 50 & 100 \\
\hline $\begin{array}{l}\text { C.Komunikasi dengan petani } \\
\text { 1. Sangattinggi } \\
\text { 2. Tinggi } \\
\text { 3. Sedang } \\
\text { 4. Rendah } \\
\text { 5. Sangatrendah }\end{array}$ & $\begin{array}{c}2 \\
18 \\
22 \\
8 \\
0\end{array}$ & $\begin{array}{c}4,00 \\
36,00 \\
44,00 \\
16,00 \\
0,00\end{array}$ \\
\hline Jumlah & 50 & 100 \\
\hline
\end{tabular}

Sumber :Data Primer 2019

Dari tabel 6 di atas dapat dilihat bahwa petani sampel yang menyatakan penyuluh berperan dalam membantu percepat arus informasi petani cabai rawit yaitu sebanyak 16,00\%.Alasan petani sampel meyatakan petani berperan karena sewaktu pemberian materi penyuluh menanyakan apakah anggota kelompok sudah menguasai dan terhadap teknologi tersebut sehingga petani mengetahui cara mana yang akan dilakukan nanti.Sedangkan $44,00 \%$ petani sampel yang menyatakan penyuluh belum memiliki kemampuan komunikasi yang baik dengan petani cabai rawit karena penyuluh menggunakan bahasa yang sulit dipahami petani sehingga petani merasa bingung untuk beradaptasi denganlingkungan.

\section{Peran Penyuluh Sebagai Evaluator}

Berdasarkan hasil penelitian terhadap 50 petani sampel,diketahui bahwa rata-rata pencapaian skor peran penyuluh sebagai evaluator sebesar 67,20\% dari skor terendah dengan kisaran 60,00\% sampai dengan 68,00\%.Secara lebih rinci frekuensi petani sampel dapat dilihat pada tabel 7.

Tabel 7. Distribusi frekuensi petani sampel berdasarkan peran penyuluh sebagai evaluator

\begin{tabular}{|l|c|c|}
\hline \multicolumn{1}{|c|}{ Kategori } & Frekuensi (orang) & Porsentase (\%) \\
\hline 1. Sangattinggi & 4 & 8,00 \\
2. Tinggi & 16 & 32,00 \\
3. Sedang & 24 & 48,00 \\
4. Rendah & 6 & 12,00 \\
5. Sangatrendah & 0 & 0,00 \\
\hline Jumlah & 50 & 100 \\
\hline
\end{tabular}

Sumber : Data Primer 2019

Berdasarkan pada tabel 12 diatas terlihat bahwa tidak ada petani yang menyatakan peran penyuluh sangat rendah.Sebagaian besar petani sampel menyatakan penyuluh telah berperan dalam menjalankan tugasnya sebesar $80,00 \%$,sedangakan $12,00 \%$ petani sampel menyatakan petani belum berperan sepenuhnya dalam menjalankan tugasnya sebagai evaluator.Dalam penelitian ini ada beberapa indikator- 
indikator yang di ukur yaitu : (i) membantu petani dalam mencari benih cabai rawit yang baik,(ii) membantu dalam pemecahan masalah budidaya usahatani tanaman cabai rawit,dan (iii) menjelaskan kepada petani yang akan menjadi keuntungan dan keunggulan pada usahatani cabai rawit.Secara lebih rinci,distribusi frekuensi petani sampel berdasarkan pada indikator-indikator tersebut disajikan pada tabel 8.

Tabel 8. Distribusi frekuensi petani sampel berdasarkan pada indikator-indikator yang diukur

\begin{tabular}{|l|c|c|}
\hline \multicolumn{1}{|c|}{ Kategori } & Frekuensi (orang) & Porsentase (\%) \\
\hline A. Membantu petani & 4 & 8,00 \\
1. Sangattinggi & 40 & 80,00 \\
2. Tinggi & 6 & 12,00 \\
3. Sedang & 0 & 0,00 \\
4. Rendah & 0 & 0,00 \\
5. Sangatrendah & 50 & 100 \\
\hline \multicolumn{1}{c|}{ Jumlah } & 2 & 4,00 \\
\hline B. Pemecahanmasalah & 42 & 84,00 \\
1. Sangattinggi & 4 & 8,00 \\
2. Tinggi & 2 & 4,00 \\
3. Sedang & 0 & 0,00 \\
4. Rendah & 50 & 100 \\
5. Sangatrendah & & 4,00 \\
\hline \multicolumn{1}{|c|}{ Jumlah } & 2 & 80,00 \\
\hline C. Keuntungan dan keunggulan & 40 & 16,00 \\
1. Sangattinggi & 8 & 0,00 \\
2. Tinggi & 0 & 0,00 \\
3. Sedang & 0 & 100 \\
4. Rendah & 50 & \\
5. Sangatrendah & & \\
\hline \multicolumn{1}{|c|}{ Jumlah } & & \\
\hline
\end{tabular}

Sumber : Data Primer 2019

Dari tabel 8 diatas dapat dilihat bahwa petani sampel yang menyatakan penyuluh berperan membantu dalam pemecahan masalah budidaya usahatani tanaman cabai rawit sangat tinggi sebesar $8,00 \%$.Alasan petani sampel karena penyuluh telah membantu petani dalam mencari benih yang baik.Sedangkan 4,00\% petani sampel menyatakan penyuluh belum berperan membantu dalam pemecahan masalah budidaya usahatani tanaman cabai rawit.Alasan petani sampel karena menurut petani penyuluh belum dapat memberikan solusi bagaimana meningkatkan teknologi budidaya usaha tanaman cabai rawit.

\section{PENUTUP}

\section{Simpulan}

Berdasarkan hasil analisis yang telah dilakukan terhadap peran penyuluh pertanian dalam peningkatan teknologi budidaya usahatani cabai rawit di Subak Cau Beten, Desa Sukawati, Kecamatan Sukawati, Kabupaten Gianyar sudah berperan dalam menjalankan tugasnya sebagai edukator dengan ratarata pencapain skor $78,00 \%$ dengan kisaran $68,00 \%$ sampai dengan $88,00 \%$ dan motivator dengan ratarata pencapaian skor adalah $77,60 \%$ dari skor tertinggi dengan kisaran $69,00 \%$ sampai dengan $82,00 \%$. Sedangkan penyuluh belum menjalankan tugasnya sebagai komunikator dengan pencapaian skor rata-rata adalah $66,40 \%$ dari skor terendah dengan kisaran $64,00 \%$ sampai dengan $68,00 \%$ dan evaluator rata-rata 
pencapaian sebesar 67,20\% dari skor terendah dengan kisaran 60,00\% sampai dengan 68,00\% .

\section{Saran}

Dari kesimpulan di atas maka, dapat disarankan kepada penyuluh agar melaksanakan peranya sebagai komunikator dan evaluator dalam peningkatan teknologi budidaya usahatani cabai rawit untuk mencapai hasil yang efisien dan efektif.

\section{DAFTARPUSTAKA}

Jasmal. 2007. Memberdayakan-Kelompok-Tani. Yogyakarta .

Kartasapoetra. A.G. 1987. Teknologi Penyuluhan Pertanian. Jakarta. Bina Aksara.

Kartasapoetra,A.G.1994. Teknologi Penyuluhan Pertanian. Jakarta. Bumi Aksara.

Mardikanto,Totok. 2009. Sistem penyuluhan Pertanian. Surakarta. Sebelas Maret University Press.

Samsudin S,U.1994. Manajemen Penyuluhan Pertanian. Bandung. Bina Cipta.

G Sedana, ND Astawa. 2019. Establishment of inclusive business on coffee production in Bali province: lesson from the coffee development project in Nusa Tenggara Timur province, Indonesia. Asian Journal of Agriculture and rural Development 9 (1), 111-122.

Sedana, G. 2018. Challenges of Rural Credit Institution to Accelerate Rural Economy: Case of Traditional Villages in Bali Province, Indonesia. International Journal of Advanced Engineering and Management Research 3 (4): 38-49.

Sedana, G. and A. Rahmat. 2020. Alternatives Policies to Strengthen the Traditional Irrigation System for Suportting the Food Security Program: Case of the Subaks' System in Bali, Indonesia. International Journal of Advanced Science and Technology 29 (7s), 973-984.

Van Den Ban Dan Hawkins. 1999. Penyuluhan Pertanian.Yoyakarta. 